\title{
BMJ Open A cluster randomised trial of cloth masks compared with medical masks in healthcare workers
}

\author{
C Raina MacIntyre, ${ }^{1}$ Holly Seale, ${ }^{1}$ Tham Chi Dung, ${ }^{2}$ Nguyen Tran Hien, ${ }^{2}$ \\ Phan Thi Nga, ${ }^{2}$ Abrar Ahmad Chughtai, ${ }^{1}$ Bayzidur Rahman, ${ }^{1}$ Dominic E Dwyer, ${ }^{3}$ \\ Quanyi Wang ${ }^{4}$
}

To cite: MacIntyre CR, Seale H, Dung TC, et al. A cluster randomised trial of cloth masks compared with medical masks in healthcare workers. BMJ Open 2015;5: e006577. doi:10.1136/ bmjopen-2014-006577

- Prepublication history for this paper is available online. To view these files please visit the journal online (http://dx.doi.org/10.1136/ bmjopen-2014-006577).

Received 9 September 2014 Revised 25 March 2015 Accepted 26 March 2015
CrossMark

For numbered affiliations see end of article.

Correspondence to Professor C Raina MacIntyre; r.macintyre@unsw.edu.au

\section{ABSTRACT}

Objective: The aim of this study was to compare the efficacy of cloth masks to medical masks in hospital healthcare workers (HCWs). The null hypothesis is that there is no difference between medical masks and cloth masks.

Setting: 14 secondary-level/tertiary-level hospitals in Hanoi, Vietnam.

Participants: 1607 hospital HCWs aged $\geq 18$ years working full-time in selected high-risk wards.

Intervention: Hospital wards were randomised to: medical masks, cloth masks or a control group (usual practice, which included mask wearing). Participants used the mask on every shift for 4 consecutive weeks.

Main outcome measure: Clinical respiratory illness (CRI), influenza-like illness (ILI) and laboratoryconfirmed respiratory virus infection.

Results: The rates of all infection outcomes were highest in the cloth mask arm, with the rate of ILI statistically significantly higher in the cloth mask arm (relative risk $(\mathrm{RR})=13.00,95 \% \mathrm{Cl} 1.69$ to 100.07 ) compared with the medical mask arm. Cloth masks also had significantly higher rates of ILI compared with the control arm. An analysis by mask use showed ILI (RR=6.64, 95\% Cl 1.45 to 28.65) and laboratoryconfirmed virus ( $R R=1.72,95 \% \mathrm{Cl} 1.01$ to 2.94 ) were significantly higher in the cloth masks group compared with the medical masks group. Penetration of cloth masks by particles was almost $97 \%$ and medical masks $44 \%$.

Conclusions: This study is the first RCT of cloth masks, and the results caution against the use of cloth masks. This is an important finding to inform occupational health and safety. Moisture retention, reuse of cloth masks and poor filtration may result in increased risk of infection. Further research is needed to inform the widespread use of cloth masks globally. However, as a precautionary measure, cloth masks should not be recommended for HCWs, particularly in high-risk situations, and guidelines need to be updated.

Trial registration number: Australian New Zealand Clinical Trials Registry: ACTRN12610000887077.

\section{Strengths and limitations of this study}

- The use of cloth masks is widespread around the world, particularly in countries at high-risk for emerging infections, but there have been no efficacy studies to underpin their use.

- This study is large, a prospective randomised clinical trial (RCT) and the first RCT ever conducted of cloth masks.

- The use of cloth masks are not addressed in most guidelines for health care workers-this study provides data to update guidelines.

- The control arm was 'standard practice', which comprised mask use in a high proportion of participants. As such (without a no-mask control), the finding of a much higher rate of infection in the cloth mask arm could be interpreted as harm caused by cloth masks, efficacy of medical masks, or most likely a combination of both.

\section{INTRODUCTION}

The use of facemasks and respirators for the protection of healthcare workers (HCWs) has received renewed interest following the 2009 influenza pandemic, ${ }^{1}$ and emerging infectious diseases such as avian influenza, ${ }^{2}$ Middle East respiratory syndrome coronavirus (MERS-coronavirus) ${ }^{3} \quad 4$ and Ebola virus. ${ }^{5}$ Historically, various types of cloth/ cotton masks (referred to here after as 'cloth masks') have been used to protect HCWs. ${ }^{6}$ Disposable medical/surgical masks (referred to here after as 'medical masks') were introduced into healthcare in the mid 19th century, followed later by respirators. ${ }^{7}$ Compared with other parts of the world, the use of face masks is more prevalent in Asian countries, such as China and Vietnam..$^{8-11}$

In high resource settings, disposable medical masks and respirators have long since replaced the use of cloth masks in hospitals. Yet cloth masks remain widely used 
globally, including in Asian countries, which have historically been affected by emerging infectious diseases, as well as in West Africa, in the context of shortages of personal protective equipment (PPE). ${ }^{12}{ }^{13}$ It has been shown that medical research disproportionately favours diseases of wealthy countries, and there is a lack of research on the health needs of poorer countries. ${ }^{14}$ Further, there is a lack of high-quality studies around the use of facemasks and respirators in the healthcare setting, with only four randomised clinical trials (RCTs) to date. ${ }^{15}$ Despite widespread use, cloth masks are rarely mentioned in policy documents, ${ }^{16}$ and have never been tested for efficacy in a RCT. Very few studies have been conducted around the clinical effectiveness of cloth masks, and most available studies are observational or in vitro. ${ }^{6}$ Emerging infectious diseases are not constrained within geographical borders, so it is important for global disease control that use of cloth masks be underpinned by evidence. The aim of this study was to determine the efficacy of cloth masks compared with medical masks in HCWs working in high-risk hospital wards, against the prevention of respiratory infections.

\section{METHODS}

A cluster-randomised trial of medical and cloth mask use for HCWs was conducted in 14 hospitals in Hanoi, Vietnam. The trial started on the 3 March 2011, with rolling recruitment undertaken between 3 March 2011 and 10 March 2011. Participants were followed during the same calendar time for 4 weeks of facemasks use and then one additional week for appearance of symptoms. An invitation letter was sent to 32 hospitals in
Hanoi, of which 16 agreed to participate. One hospital did not meet the eligibility criteria; therefore, 74 wards in 15 hospitals were randomised. Following the randomisation process, one hospital withdrew from the study because of a nosocomial outbreak of rubella.

Participants provided written informed consent prior to initiation of the trial.

\section{Randomisation}

Seventy-four wards (emergency, infectious/respiratory disease, intensive care and paediatrics) were selected as high-risk settings for occupational exposure to respiratory infections. Cluster randomisation was used because the outcome of interest was respiratory infectious diseases, where prevention of one infection in an individual can prevent a chain of subsequent transmission in closed settings. ${ }^{8} 9$ Epi info V.6 was used to generate a randomisation allocation and 74 wards were randomly allocated to the interventions.

From the eligible wards $1868 \mathrm{HCWs}$ were approached to participate. After providing informed consent, 1607 participants were randomised by ward to three arms: (1) medical masks at all times on their work shift; (2) cloth masks at all times on shift or (3) control arm (standard practice, which may or may not include mask use). Standard practice was used as control because the IRB deemed it unethical to ask participants to not wear a mask. We studied continuous mask use (defined as wearing masks all the time during a work shift, except while in the toilet or during tea or lunch breaks) because this reflects current practice in high-risk settings in Asia. ${ }^{8}$
Figure 1 Consort diagram of recruitment and follow-up (HCWs, healthcare workers).

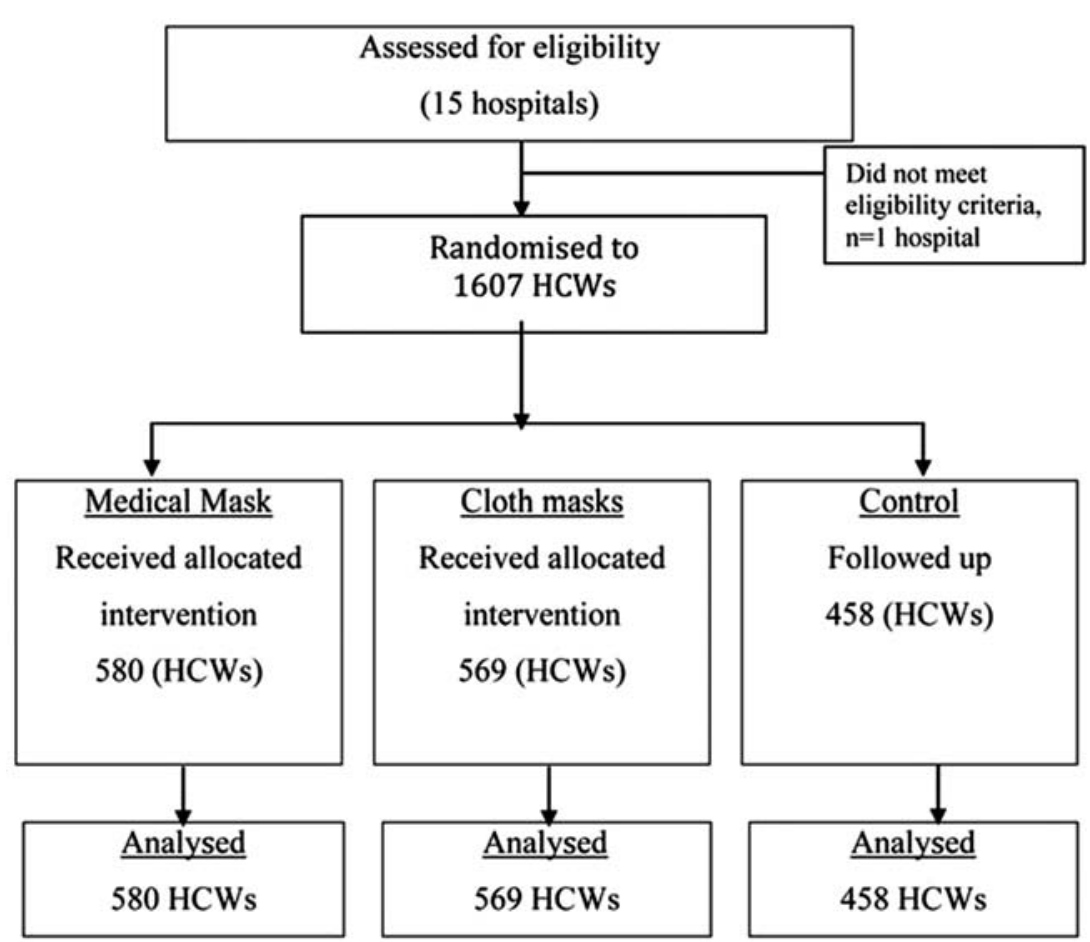


The laboratory results were blinded and laboratory testing was conducted in a blinded fashion. As facemask use is a visible intervention, clinical end points could not be blinded. Figure 1 outlines the recruitment and randomisation process.

\section{Primary end points}

There were three primary end points for this study, used in our previous mask RCTs: ${ }^{8}$ (1) Clinical respiratory illness (CRI), defined as two or more respiratory symptoms or one respiratory symptom and a systemic symptom; ${ }^{17}$ (2) influenza-like illness (ILI), defined as fever $\geq 38^{\circ} \mathrm{C}$ plus one respiratory symptom and (3) laboratory-confirmed viral respiratory infection. Laboratory confirmation was by nucleic acid detection using multiplex reverse transcriptase PCR (RT-PCR) for 17 respiratory viruses: respiratory syncytial virus (RSV) A and B, human metapneumovirus (hMPV), influenza A (H3N2), (H1N1)pdm09, influenza $\mathrm{B}$, parainfluenza viruses 1-4, influenza $\mathrm{C}$, rhinoviruses, severe acute respiratory syndrome (SARS) associated coronavirus (SARS-CoV), coronaviruses 229E, NL63, OC43 and HKU1, adenoviruses and human bocavirus $(\mathrm{hBoV}) .{ }^{18-23}$ Additional end points included compliance with mask use, defined as using the mask during the shift for $70 \%$ or more of work shift hours. ${ }^{9}$ HCWs were categorised as 'compliant' if the average use was equal or more than $70 \%$ of the working time. HCW were categorised as 'non-compliant' if the average mask use was less than $70 \%$ of the working time.

\section{Eligibility}

Nurses or doctors aged $\geq 18$ years working full-time were eligible. Exclusion criteria were: (1) Unable or refused to consent; (2) Beards, long moustaches or long facial hair stubble; (3) Current respiratory illness, rhinitis and/or allergy.

\section{Intervention}

Participants wore the mask on every shift for four consecutive weeks. Participants in the medical mask arm were supplied with two masks daily for each $8 \mathrm{~h}$ shift, while participants in the cloth mask arm were provided with five masks in total for the study duration, which they were asked to wash and rotate over the study period. They were asked to wash cloth masks with soap and water every day after finishing the shifts. Participants were supplied with written instructions on how to clean their cloth masks. Masks used in the study were locally manufactured medical (three layer, made of non-woven material) or cloth masks (two layer, made of cotton) commonly used in Vietnamese hospitals. The control group was asked to continue with their normal practices, which may or may not have included mask wearing. Mask wearing was measured and documented for all participants, including the control arm.
Data collection and follow-up

Data on sociodemographic, clinical and other potential confounding factors were collected at baseline. Participants were followed up daily for 4 weeks (active intervention period), and for an extra week of standard practice, in order to document incident infection after incubation. Participants received a thermometer (traditional glass and mercury) to measure their temperature daily and at symptom onset. Daily diary cards were provided to record number of hours worked and mask use, estimated number of patient contacts (with/without ILI) and number/type of aerosol-generating procedures (AGPs) conducted, such as suctioning of airways, sputum induction, endotracheal intubation and bronchoscopy. Participants in the cloth mask and control group (if they used cloth masks) were also asked to document the process used to clean their mask after use.

We also monitored compliance with mask use by a previously validated self-reporting mechanism. ${ }^{8}$ Participants were contacted daily to identify incident cases of respiratory infection. If participants were symptomatic, swabs of both tonsils and the posterior pharyngeal wall were collected on the day of reporting.

\section{Sample collection and laboratory testing}

Trained collectors used double rayon-tipped, plasticshafted swabs to scratch tonsillar areas as well as the posterior pharyngeal wall of symptomatic participants. Testing was conducted using RT-PCR applying published methods. ${ }^{19-23}$ Viral RNA was extracted from each respiratory specimen using the Viral RNA Mini kit (Qiagen, Germany), following the manufacturer's instructions. The RNA extraction step was controlled by amplification of a RNA house-keeping gene (amplify pGEM) using real-time RT-PCR. Only extracted samples with the house keeping gene detected by real-time RT-PCR were submitted for multiplex RT-PCR for viruses.

The reverse transcription and PCRs were performed in OneStep (Qiagen, Germany) to amplify viral target genes, and then in five multiplex RT-PCR: RSVA/B, influenza A/H3N2, $\mathrm{A}(\mathrm{H} 1 \mathrm{~N} 1)$ and $\mathrm{B}$ viruses, hMPV (reaction mix 1); parainfluenza viruses 1-4 (reaction mix 2); rhinoviruses, influenza $\mathrm{C}$ virus, SARS-CoV (reaction mix 3); coronaviruses OC43, 229E, NL63 and HKU1 (reaction mix 4); and adenoviruses and $\mathrm{hBoV}$ (reaction mix 5), using a method published by others. ${ }^{18}$ All samples with viruses detected by multiplex RT-PCR were confirmed by virus-specific mono nested or heminested PCR. Positive controls were prepared by in vitro transcription to control amplification efficacy and monitor for false negatives, and included in all runs (except for NL63 and HKU1). Each run always included two negatives to monitor amplification quality. Specimen processing, RNA extraction, PCR amplification and PCR product analyses were conducted in different rooms to avoid cross-contamination. ${ }^{19} 20$ 


\section{Filtration testing}

The filtration performance of the cloth and medical masks was tested according to the respiratory standard AS/NZS1716. ${ }^{24}$ The equipment used was a TSI 8110 Filter tester. To test the filtration performance, the filter is challenged by a known concentration of sodium chloride particles of a specified size range and at a defined flow rate. The particle concentration is measured before and after adding the filter material and the relative filtration efficiency is calculated. We examined the performance of cloth masks compared with the performance levels-P1, P2 (=N95) and P3, as used for assessment of all particulate filters for respiratory protection. The 3M 9320 N95 and 3M Vflex 9105 N95 were used to compare against the cloth and medical masks.

\section{Sample size calculation}

To obtain $80 \%$ power at two-sided $5 \%$ significance level for detecting a significant difference of attack rate between medical masks and cloth masks, and for a rate of infection of $13 \%$ for cloth mask wearers compared with $6 \%$ in medical mask wearers, we would need eight clusters per arm and 530 participants in each arm, and intracluster correlation coefficient (ICC) 0.027, obtained from our previous study. ${ }^{8}$ The design effect (deff) for this cluster randomisation trial was $1.65 \quad(\mathrm{deff}=1+(\mathrm{m}$ $-1) \times \mathrm{ICC}=1+(25-1) \times 0.027=1.65)$. As such, we aimed to recruit a sample size of 1600 participants from up to 15 hospitals.

\section{Analysis}

Descriptive statistics were compared among intervention and control arms. Primary end points were analysed by intention to treat. We compared the event rates for the primary outcomes across study arms and calculated $\mathrm{p}$ values from cluster-adjusted $\chi^{2}$ tests $^{25}$ and ICC. ${ }^{25}{ }^{26} \mathrm{We}$ also estimated relative risk (RR) after adjusting for clustering using a log-binomial model under generalised estimating equation (GEE) framework. ${ }^{27}$ We checked for variables which were unequally distributed across arms, and conducted an adjusted analysis accordingly. We fitted a multivariable log-binomial model, using GEE to account for clustering by ward, to estimate RR after adjusting for potential confounders. In the initial model, we included all the variables that had $p$ value less than 0.25 in the univariable analysis, along with the main exposure variable (randomisation arm). A backward elimination method was used to remove the variables that did not have any confounding effect.

As most participants in the control arm used a mask during the trial period, we carried out a post-hoc analysis comparing all participants who used only a medical mask (from the control arm and the medical mask arm) with all participants who used only a cloth mask (from the control arm and the cloth arm). For this analysis, controls who used both types of mask $(n=245)$ or used N95 respirators $(n=3)$ or did not use any masks $(n=2)$ were excluded. We fitted a multivariable log-binomial model, to estimate RR after adjusting for potential confounders. As we pooled data of participants from all three arms and analysed by mask type, not trial arm, we did not adjust for clustering here. All statistical analyses were conducted using STATA V.12. ${ }^{28}$

Owing to a very high level of mask use in the control arm, we were unable to determine whether the differences between the medical and cloth mask arms were due to a protective effect of medical masks or a detrimental effect of cloth masks. To assist in interpreting the data, we compared rates of infection in the medical mask arm with rates observed in medical mask arms from two previous RCTs, ${ }^{8}{ }^{9}$ in which no efficacy of medical masks could be demonstrated when compared with control or N95 respirators, recognising that seasonal and geographic variation in virus activity affects the rates of exposure (and hence rates of infection outcomes) among HCWs. This analysis was possible because the trial designs were similar and the same outcomes were measured in all three trials. The analysis was carried out to determine if the observed results were explained by a detrimental effect of cloth masks or a protective effect of medical masks.

\section{RESULTS}

A total of 1607 HCWs were recruited into the study. The participation rate was $86 \%(1607 / 1868)$. The average number of participants per ward was 23 and the mean age was 36 years. On average, HCWs were in contact with 36 patients per day during the trial period (range 0-661 patients per day, median 20 patients per day). The distribution of demographic variables was generally similar between arms (table 1). Figure 2 shows the primary outcomes for each of the trial arms. The rates of CRI, ILI and laboratory-confirmed virus infections were lowest in the medical mask arm, followed by the control arm, and highest in the cloth mask arm.

Table 2 shows the intention-to-treat analysis. The rate of CRI was highest in the cloth mask arm, followed by the control arm, and lowest in the medical mask arm. The same trend was seen for ILI and laboratory tests confirmed viral infections. In intention-to-treat analysis, ILI was significantly higher among HCWs in the cloth masks group ( $\mathrm{RR}=13.25$ and $95 \%$ CI 1.74 to 100.97), compared with the medical masks group. The rate of ILI was also significantly higher in the cloth masks arm $(\mathrm{RR}=3.49$ and $95 \%$ CI 1.00 to 12.17$)$, compared with the control arm. Other outcomes were not statistically significant between the three arms.

Among the 68 laboratory-confirmed cases, 58 (85\%) were due to rhinoviruses. Other viruses detected were hMPV ( 7 cases), influenza B (1 case), hMPV/rhinovirus co-infection ( 1 case) and influenza $B /$ rhinovirus co-infection (1 case) (table 3). No influenza A or RSV infections were detected.

Compliance was significantly higher in the cloth mask arm ( $R R=2.41,95 \%$ CI 2.01 to 2.88$)$ and medical masks 
Table 1 Demographic and other characteristics by arm of randomisation

\begin{tabular}{|c|c|c|c|}
\hline Variable & $\begin{array}{l}\text { Medical mask } \\
(\% \text { and } 95 \% \mathrm{Cl}) \\
(\mathrm{n}=580)\end{array}$ & $\begin{array}{l}\text { Cloth mask } \\
(\% \text { and } 95 \% \mathrm{Cl}) \\
(\mathrm{n}=569)\end{array}$ & $\begin{array}{l}\text { Control } \\
(\% \text { and } 95 \% \mathrm{Cl}) \\
(\mathrm{n}=458)\end{array}$ \\
\hline \multirow[t]{2}{*}{ Gender (male) } & $112 / 580$ & $133 / 569$ & $112 / 458$ \\
\hline & 19.3 (16.2 to 22.8$)$ & 23.4 (20.0 to 27.1$)$ & 24.5 (20.6 to 28.7$)$ \\
\hline Age (mean) & 36 (35.6 to 37.3$)$ & 35 (34.6 to 36.3$)$ & 36 (35.1 to 37.0$)$ \\
\hline \multirow[t]{2}{*}{ Education (postgraduate) } & $114 / 580$ & 99/569 & $78 / 458$ \\
\hline & 19.7 (16.5 to 23.1$)$ & 17.4 (14.3 to 20.8$)$ & $17.0(13.7$ to 20.8$)$ \\
\hline \multirow[t]{2}{*}{ Smoker (current/ex) } & $78 / 580$ & $79 / 569$ & $66 / 458$ \\
\hline & 13.4 (10.8 to 16.5$)$ & $13.9(11.1$ to 17.0$)$ & $14.4(11.3$ to 18.0$)$ \\
\hline \multirow[t]{2}{*}{ Pre-existing illness* } & $66 / 580$ & $70 / 569$ & $47 / 458$ \\
\hline & 11.4 (9.0 to 14.2$)$ & $12.3(9.8$ to 15.3$)$ & $10.3(7.8$ to 13.4$)$ \\
\hline \multirow[t]{2}{*}{ Influenza vaccination (yes) } & $21 / 580$ & $21 / 569$ & $15 / 458$ \\
\hline & $3.6(2.4$ to 5.4$)$ & 3.7 (2.4 to 5.6$)$ & 3.3 (2.0 to 5.3$)$ \\
\hline \multirow[t]{2}{*}{ Staff (doctors) } & $176 / 580$ & $165 / 569$ & $134 / 458$ \\
\hline & 30.3 (26.6 to 34.3$)$ & 29.0 (25.3 to 32.9$)$ & $29.3(25.1$ to 33.7$)$ \\
\hline $\begin{array}{l}\text { Number of hand washings per day } \\
\text { (geometric mean)† }\end{array}$ & $14(13.8$ to 15.4$)$ & 11 (10.9 to 11.9 ) & 12 (11.5 to 12.7$)$ \\
\hline $\begin{array}{l}\text { Number of patients had contact with } \\
\text { (median and range) } \ddagger\end{array}$ & $21(0$ to 540$)$ & 21 (0 to 661) & 18 (3 to 199$)$ \\
\hline
\end{tabular}

arm ( $R R=2.40,95 \%$ CI 2.00 to 2.87$)$, compared with the control arm. Figure 3 shows the percentage of participants who were compliant in the three arms. A post-hoc analysis adjusted for compliance and other potential confounders showed that the rate of ILI was significantly higher in the cloth mask arm ( $R R=13.00$, 95\% CI 1.69 to 100.07), compared with the medical masks arm (table 4). There was no significant difference between the medical mask and control arms. Hand washing was significantly protective against laboratory-confirmed viral infection ( $\mathrm{RR}=0.66,95 \%$ CI 0.44 to 0.97$)$.

In the control arm, $170 / 458(37 \%)$ used medical masks, 38/458 (8\%) used cloth masks, and 245/458 $(53 \%)$ used a combination of both medical and cloth masks during the study period. The remaining $1 \%$

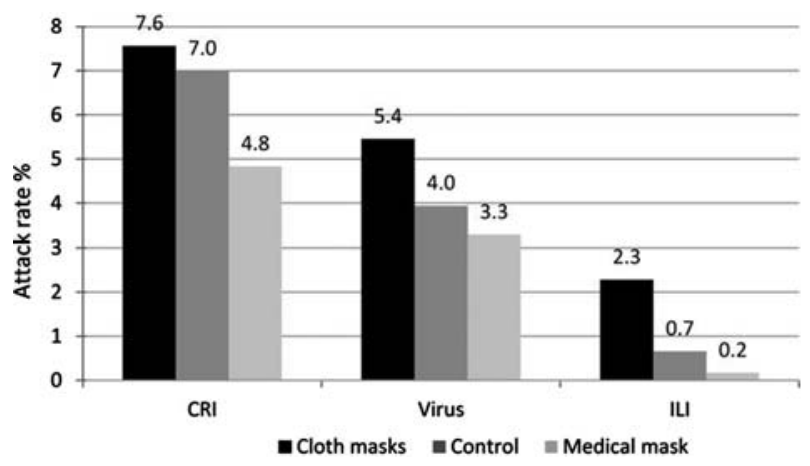

Figure 2 Outcomes in trial arms (CRI, clinical respiratory illness; ILI, influenza-like illness; Virus, laboratory-confirmed viruses). either reported using a N95 respirator $(n=3)$ or did not use any masks $(n=2)$.

Table 5 shows an additional analysis comparing all participants who used only a medical mask (from the control arm and the medical mask arm) with all participants who used only a cloth mask (from the control arm and the cloth arm). In the univariate analysis, all outcomes were significantly higher in the cloth mask group, compared with the medical masks group. After adjusting for other factors, ILI ( $R R=6.64,95 \%$ CI 1.45 to 28.65) and laboratory-confirmed virus $(\mathrm{RR}=1.72,95 \%$ CI 1.01 to 2.94 ) remained significantly higher in the cloth masks group compared with the medical masks group.

Table 6 compares the outcomes in the medical mask arm with two previously published trials. ${ }^{8}{ }^{9}$ This shows that while the rates of CRI were significantly higher in one of the previously published trials, the rates of laboratory-confirmed viruses were not significantly different between the three trials for medical mask use.

On average, HCWs worked for 25 days during the trial period and washed their cloth masks for 23/25 (92\%) days. The most common approach to washing cloth masks was self-washing $(456 / 569,80 \%)$, followed by combined self-washing and hospital laundry (91/569, $16 \%)$, and only hospital laundry $(22 / 569,4 \%)$. Adverse events associated with facemask use were reported in $40.4 \%(227 / 562)$ of HCWs in the medical mask arm and $42.6 \%(242 / 568)$ in the cloth mask arm ( $\mathrm{p}$ value 0.450). General discomfort (35.1\%, 397/1130) and breathing problems $(18.3 \%, 207 / 1130)$ were the most frequently reported adverse events. 
Table 2 Intention-to-treat analysis

\begin{tabular}{|c|c|c|c|c|c|c|}
\hline & $\begin{array}{l}\text { CRI } \\
\text { N (\%) }\end{array}$ & $\begin{array}{l}\text { RR } \\
\text { (95\% Cl) }\end{array}$ & $\begin{array}{l}\text { ILI } \\
\text { N (\%) }\end{array}$ & $\begin{array}{l}\text { RR } \\
(95 \% \mathrm{CI})\end{array}$ & $\begin{array}{l}\text { Laboratory- } \\
\text { confirmed } \\
\text { viruses } \\
\mathrm{N}(\%)\end{array}$ & $\begin{array}{l}\text { RR } \\
(95 \% \mathrm{Cl})\end{array}$ \\
\hline Medical mask* & $28 / 580(4.83)$ & Ref & $1 / 580(0.17)$ & Ref & $19 / 580(3.28)$ & Ref \\
\hline Cloth masks $†$ & $43 / 569(7.56)$ & 1.57 (0.99 to 2.48$)$ & $13 / 569(2.28)$ & 13.25 (1.74 to 100.97$)$ & $31 / 569(5.45)$ & 1.66 (0.95 to 2.91$)$ \\
\hline Control & $32 / 458(6.99)$ & $1.45(0.88$ to 2.37$)$ & $3 / 458(0.66)$ & 3.80 (0.40 to 36.40$)$ & $18 / 458(3.94)$ & 1.20 (0.64 to 2.26$)$ \\
\hline
\end{tabular}

Laboratory tests showed the penetration of particles through the cloth masks to be very high (97\%) compared with medical masks $(44 \%)$ (used in trial) and $3 \mathrm{M}$ 9320 N95 $(<0.01 \%)$, 3M Vflex 9105 N95 (0.1\%).

\section{DISCUSSION}

We have provided the first clinical efficacy data of cloth masks, which suggest HCWs should not use cloth masks as protection against respiratory infection. Cloth masks resulted in significantly higher rates of infection than medical masks, and also performed worse than the control arm. The controls were HCWs who observed standard practice, which involved mask use in the majority, albeit with lower compliance than in the intervention arms. The control HCWs also used medical masks more often than cloth masks. When we analysed all mask-wearers including controls, the higher risk of cloth masks was seen for laboratory-confirmed respiratory viral infection.

The trend for all outcomes showed the lowest rates of infection in the medical mask group and the highest rates in the cloth mask arm. The study design does not allow us to determine whether medical masks had efficacy or whether cloth masks were detrimental to HCWs by causing an increase in infection risk. Either possibility, or a combination of both effects, could explain our results. It is also unknown whether the rates of infection observed in the cloth mask arm are the same or higher than in HCWs who do not wear a mask, as almost all participants in the control arm used a mask. The physical properties of a cloth mask, reuse, the frequency and effectiveness of cleaning, and increased moisture retention, may potentially increase the infection risk for
HCWs. The virus may survive on the surface of the facemasks, ${ }^{29}$ and modelling studies have quantified the contamination levels of masks. ${ }^{30}$ Self-contamination through repeated use and improper doffing is possible. For example, a contaminated cloth mask may transfer pathogen from the mask to the bare hands of the wearer. We also showed that filtration was extremely poor (almost $0 \%$ ) for the cloth masks. Observations during SARS suggested double-masking and other practices increased the risk of infection because of moisture, liquid diffusion and pathogen retention. ${ }^{31}$ These effects may be associated with cloth masks.

We have previously shown that N95 respirators provide superior efficacy to medical masks, ${ }^{8} 9$ but need to be worn continuously in high-risk settings to protect HCWs. ${ }^{9}$ Although efficacy for medical masks was not shown, efficacy of a magnitude that was too small to be detected is possible. ${ }^{8} 9$ The magnitude of difference between cloth masks and medical masks in the current study, if explained by efficacy of medical masks alone, translates to an efficacy of $92 \%$ against ILI, which is possible, but not consistent with the lack of efficacy in the two previous RCTs. ${ }^{8}{ }^{9}$ Further, we found no significant difference in rates of virus isolation in medical mask users between the three trials, suggesting that the results of this study could be interpreted as partly being explained by a detrimental effect of cloth masks. This is further supported by the fact that the rate of virus isolation in the no-mask control group in the first Chinese RCT was $3.1 \%$, which was not significantly different to the rates of virus isolation in the medical mask arms in any of the three trials including this one. Unlike the previous RCTs, circulating influenza and RSV were almost completely absent during this study,

Table 3 Type of virus isolated

\begin{tabular}{|c|c|c|c|c|c|c|}
\hline Study arm & hMPV & Rhino & $\begin{array}{l}\text { Influenza } \\
\text { B virus }\end{array}$ & $\begin{array}{l}\text { hMPV \& } \\
\text { rhino }\end{array}$ & $\begin{array}{l}\text { Influenza } \\
\text { B virus \& rhino }\end{array}$ & Total \\
\hline Medical masks arm & 1 & 16 & 1 & 1 & 0 & 19 \\
\hline Cloth mask arm & 4 & 26 & 0 & 0 & 1 & 31 \\
\hline Control arm & 2 & 16 & 0 & 0 & 0 & 18 \\
\hline Total & 7 & 58 & 1 & 1 & 1 & 68 \\
\hline
\end{tabular}




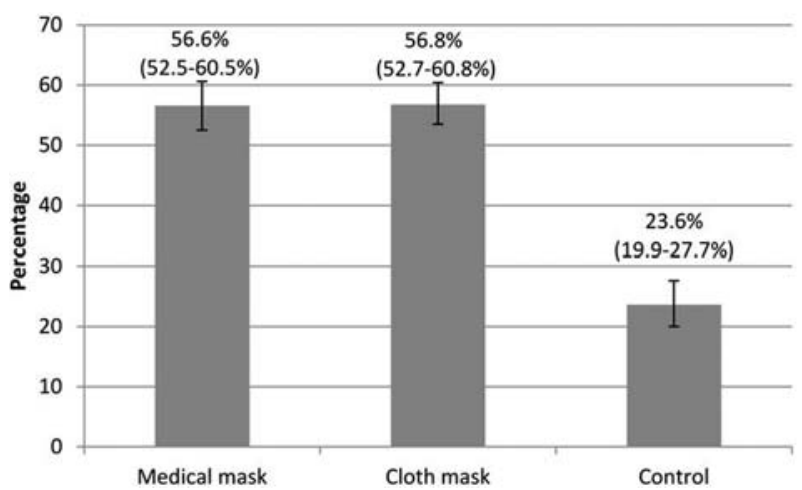

Figure 3 Compliance with the mask wearing-mask wearing more than $70 \%$ of working hours.

with rhinoviruses comprising $85 \%$ of isolated pathogens, which means the measured efficacy is against a different range of circulating respiratory pathogens. Influenza and RSV predominantly transmit through droplet and contact routes, while Rhinovirus transmits through multiple routes, including airborne and droplet routes. ${ }^{32} 33$ The data also show that the clinical case definition of ILI is non-specific, and captures a range of pathogens other than influenza. The study suggests medical masks may be protective, but the magnitude of difference raises the possibility that cloth masks cause an increase in infection risk in HCWs. Further, the filtration of the medical mask used in this trial was poor, making extremely high efficacy of medical masks unlikely, particularly given the predominant pathogen was rhinovirus, which spreads by the airborne route. Given the obligations to HCW occupational health and safety, it is important to consider the potential risk of using cloth masks.

In many parts of the world, cloth masks and medical masks may be the only options available for HCWs. Cloth masks have been used in West Africa during the Ebola outbreak in 2014, due to shortages of PPE, (personal communication, M Jalloh). The use of cloth masks is recommended by some health organisations, with caveats. ${ }^{34-36}$ In light of our study, and the obligation to ensure occupational health and safety of HCWs, cloth masks should not be recommended for HCWs, particularly during AGPs and in high-risk settings such as emergency, infectious/respiratory disease and intensive care wards. Infection control guidelines need to acknowledge the widespread real-world practice of cloth masks and should comprehensively address their use. In addition, other important infection control measure such as hand hygiene should not be compromised. We confirmed the protective effects of hand hygiene against laboratoryconfirmed viral infection in this study, but mask type was an independent predictor of clinical illness, even adjusted for hand hygiene.

A limitation of this study is that we did not measure compliance with hand hygiene, and the results reflect self-reported compliance, which may be subject to recall or other types of bias. Another limitation of this study is the lack of a no-mask control group and the high use of masks in the controls, which makes interpretation of the results more difficult. In addition, the quality of paper and cloth masks varies widely around the world, so the results may not be generalisable to all settings. The lack of influenza and RSV (or asymptomatic infections) during the study is also a limitation, although the predominance of rhinovirus is informative about pathogens transmitted by the droplet and airborne routes in this setting. As in previous studies, exposure to infection outside the workplace could not be estimated, but we would assume it to be equally distributed between trial arms. The major strength of the randomised trial study design is in ensuring equal distribution of confounders and effect modifiers (such as exposure outside the workplace) between trial arms.

Cloth masks are used in resource-poor settings because of the reduced cost of a reusable option. Various types of cloth masks (made of cotton, gauze and other fibres) have been tested in vitro in the past and show lower filtration capacity compared with disposable masks. ${ }^{7}$ The protection afforded by gauze masks increases with the fineness of the cloth and the number of layers, ${ }^{37}$ indicating potential to develop a more effective cloth mask, for example, with finer weave, more layers and a better fit.

Cloth masks are generally retained long term and reused multiple times, with a variety of cleaning methods and widely different intervals of cleaning. ${ }^{34}$ Further studies are required to determine if variations in frequency and type of cleaning affect the efficacy of cloth masks.

Table 4 Multivariable cluster-adjusted log-binomial model to calculate RR for study outcomes

\begin{tabular}{|c|c|c|c|}
\hline & $\begin{array}{l}\text { CRI } \\
\text { RR (95\% Cl) }\end{array}$ & $\begin{array}{l}\text { ILI } \\
\text { RR }(95 \% \mathrm{CI})\end{array}$ & $\begin{array}{l}\text { Laboratory-confirmed viruses } \\
\text { RR }(95 \% \mathrm{CI})\end{array}$ \\
\hline Medical masks arm & Ref & Ref & Ref \\
\hline Cloth mask arm & 1.56 (0.97 to 2.48$)$ & $13.00(1.69$ to 100.07$)$ & 1.54 (0.88 to 2.70$)$ \\
\hline Control arm & 1.51 (0.90 to 2.52$)$ & $4.64(0.47$ to 45.97$)$ & 1.09 (0.57 to 2.09$)$ \\
\hline Male & $0.67(0.41$ to 1.12$)$ & $1.03(0.34$ to 3.13$)$ & 0.65 (0.34 to 1.22$)$ \\
\hline Vaccination & 0.83 (0.27 to 2.52$)$ & $1.74(0.24$ to 12.56$)$ & 1.27 (0.41 to 3.92$)$ \\
\hline Hand washing & $0.91(0.66$ to 1.26$)$ & $0.94(0.40$ to 2.20$)$ & 0.66 (0.44 to 0.97$)$ \\
\hline Compliance & $1.14(0.77$ to 1.69$)$ & $1.86(0.67$ to 5.21$)$ & $0.86(0.53$ to 1.40$)$ \\
\hline
\end{tabular}

Bold typeface indicates statistically significant.

$\mathrm{CRI}$, clinical respiratory illness; ILI, influenza-like illness; RR, relative risk. 
Table 5 Univariate and adjusted analysis comparing participants who used medical masks and cloth masks*

\begin{tabular}{|c|c|c|}
\hline & $\begin{array}{l}\text { Univariate } \\
\text { RR (95\% Cl) }\end{array}$ & $\begin{array}{l}\text { Adjusted } \\
\text { RR }(95 \% \mathrm{CI})\end{array}$ \\
\hline \multicolumn{3}{|l|}{$\mathrm{CRI}$} \\
\hline Medical mask (35/750, 4.67\%) & Ref & Ref \\
\hline Cloth mask $(46 / 607,7.58 \%)$ & 1.62 (1.06 to 2.49$)$ & 1.51 (0.97 to 2.32$)$ \\
\hline Male & $0.60(0.32$ to 1.12$)$ & $0.58(0.31$ to 1.08$)$ \\
\hline Vaccination & 0.66 (0.17 to 2.62$)$ & $0.68(0.17$ to 2.67$)$ \\
\hline Hand washing & $0.81(0.58$ to 1.15$)$ & $0.84(0.59$ to 1.20$)$ \\
\hline Compliance & 1.01 (1.00 to 1.03$)$ & 1.01 (1.00 to 1.02$)$ \\
\hline \multicolumn{3}{|l|}{ ILI } \\
\hline Medical mask (2/750, 0.27\%) & Ref & Ref \\
\hline Cloth mask (13/607, 2.14\%) & $8.03(1.82$ to 35.45$)$ & $6.64(1.45$ to 28.65$)$ \\
\hline Male & $0.95(0.27$ to 3.35$)$ & 0.92 (0.26 to 3.22$)$ \\
\hline Vaccination & $1.87(0.25$ to 13.92$)$ & $1.97(0.27$ to 14.45$)$ \\
\hline Hand washing & $0.56(0.24$ to 1.27$)$ & $0.61(0.23$ to 1.57$)$ \\
\hline Compliance & 1.04 (1.01 to 1.08$)$ & $1.04(1.00$ to 1.08$)$ \\
\hline \multicolumn{3}{|l|}{ Laboratory-confirmed viruses } \\
\hline Medical mask (22/750, 2.93\%) & Ref & Ref \\
\hline Cloth mask $(34 / 607,5.60 \%)$ & 1.91 (1.13 to 3.23$)$ & 1.72 (1.01 to 2.94$)$ \\
\hline Male & 0.64 (0.30 to 1.33$)$ & 0.61 (0.29 to 1.27$)$ \\
\hline Vaccination & $0.97(0.24$ to 3.86$)$ & $1.03(0.26$ to 4.08$)$ \\
\hline Hand washing & $0.61(0.41$ to 0.93$)$ & $0.65(0.42$ to 1.00$)$ \\
\hline Compliance & 1.00 (0.99 to 1.02$)$ & $1.0(0.99$ to 1.02$)$ \\
\hline
\end{tabular}

Table 6 A comparison of outcome data for the medical mask arm with medical mask outcomes in previously published RCTs

\begin{tabular}{|c|c|c|c|c|c|c|}
\hline & $\begin{array}{l}\text { CRI } \\
\text { N (\%) }\end{array}$ & $\begin{array}{l}\text { RR } \\
(95 \% \mathrm{CI})\end{array}$ & $\begin{array}{l}\text { ILI } \\
\text { N (\%) }\end{array}$ & $\begin{array}{l}\text { RR } \\
(95 \% \mathrm{Cl})\end{array}$ & $\begin{array}{l}\text { Laboratory- } \\
\text { confirmed } \\
\text { viruses } \\
\mathrm{N}(\%)\end{array}$ & $\begin{array}{l}\text { RR } \\
(95 \% \mathrm{CI})\end{array}$ \\
\hline Vietnam trial & $28 / 580(4.83)$ & Ref & $1 / 580(0.17)$ & Ref & $19 / 580$ (3.28) & Ref \\
\hline $\begin{array}{l}\text { Published RCT } \\
\text { China } 1^{8}\end{array}$ & $33 / 492(6.70)$ & 1.40 (0.85 to 2.26$)$ & $3 / 492(0.61)$ & $3.53(0.37$ to 33.89$)$ & $13 / 492(2.64)$ & $0.80(0.40$ to 1.62$)$ \\
\hline $\begin{array}{l}\text { Published RCT } \\
\text { China } 2^{9}\end{array}$ & 98/572 (17.13) & 3.54 (2.37 to 5.31$)$ & $4 / 572(0.70)$ & $4.06(0.45$ to 36.18$)$ & 19/572 (3.32) & $1.01(0.54$ to 1.89$)$ \\
\hline
\end{tabular}

Pandemics and emerging infections are more likely to arise in low-income or middle-income settings than in wealthy countries. In the interests of global public health, adequate attention should be paid to cloth mask use in such settings. The data from this study provide some reassurance about medical masks, and are the first data to show potential clinical efficacy of medical masks. Medical masks are used to provide protection against droplet spread, splash and spray of blood and body fluids. Medical masks or respirators are recommended by different organisations to prevent transmission of Ebola virus, yet shortages of PPE may result in HCWs being forced to use cloth masks. ${ }^{38-40}$ In the interest of providing safe, low-cost options in low income countries, there is scope for research into more effectively designed cloth masks, but until such research is carried out, cloth masks should not be recommended. We also recommend that infection control guidelines be updated about cloth mask use to protect the occupational health and safety of HCWs.

\section{Author affiliations}

${ }^{1}$ Faculty of Medicine, School of Public Health and Community Medicine, University of New South Wales, Sydney, Australia

${ }^{2}$ National Institute of Hygiene and Epidemiology, Hanoi, Vietnam

${ }^{3}$ Institute for Clinical Pathology and Medical Research, Westmead Hospital and University of Sydney, Sydney, New South Wales, Australia

${ }^{4}$ Beijing Centers for Disease Control and Prevention, Beijing, China

Acknowledgements The authors would like to thank the staff members from the National Institute of Hygiene and Epidemiology, Hanoi, Vietnam, who were involved with the trial. They thank as well to the staff from the Hanoi hospitals who participated. They also acknowledge the support of $3 \mathrm{M}$ for testing of filtration of the facemasks. 3M was industry partner in the ARC linkage project 
grant; however they were not involved in study design, data collection or analysis. The 3M products were not used in this study.

Contributors CRM was the lead investigator, and responsible for the conception and design of the trial, obtaining the grant funding, overseeing the whole study, analysing the data and writing of the report. HS contributed to overseeing the study, staff training, form/database development and drafting of the manuscript. TCD was responsible for overseeing the study, database management, recruitment, training and revision of the manuscript. NTH was responsible for the implementation of research and revision of the manuscript. PTN was responsible for the laboratory testing in Vietnam. AAC contributed to the statistical analysis and drafting of the manuscript. BR was responsible for the statistical analysis and revision of the manuscript. DED contributed to the laboratory technical assistance and revision of the manuscript. QW assisted in comparing the rates of infection from two previous RCTs conducted in China and revision of the manuscript.

Funding Funding to conduct this study was received from the Australian Research Council (ARC) (grant number LP0990749).

Competing interests CRM has held an Australian Research Council Linkage Grant with $3 \mathrm{M}$ as the industry partner, for investigator-driven research. 3M has also contributed masks and respirators for investigator-driven clinical trials. CRM has received research grants and laboratory testing as in-kind support from Pfizer, GSK and Bio-CSL for investigator-driven research. HS had a NHMRC Australian-based Public Health Training Fellowship at the time of the study (1012631). She has also received funding from vaccine manufacturers GSK, bio-CSL and Sanofi Pasteur for investigator-driven research and presentations. AAC used filtration testing of masks for his $\mathrm{PhD}$ thesis conducted by 3M Australia.

Ethics approval National Institute for Hygiene and Epidemiology (NIHE) (approval number 05 IRB) and the Human Research Ethics Committee of the University of New South Wales (UNSW), Australia, (HREC approval number 10306).

Provenance and peer review Not commissioned; externally peer reviewed.

Data sharing statement No additional data are available.

Open Access This is an Open Access article distributed in accordance with the Creative Commons Attribution Non Commercial (CC BY-NC 4.0) license, which permits others to distribute, remix, adapt, build upon this work noncommercially, and license their derivative works on different terms, provided the original work is properly cited and the use is non-commercial. See: http:// creativecommons.org/licenses/by-nc/4.0/

\section{REFERENCES}

1. World Health Organization (WHO). Global Alert and Response (GAR), Pandemic (H1N1) 2009-update 76 (cited 27 Apr 2012). http://www.who.int/csr/don/2009_11_27a/en/index.html

2. World Health Organization (WHO). Human infection with avian influenza A(H7N9) virus—update (cited 8 May 2013). http://www. who.int/csr/don/2013_05_07/en/index.html

3. Bermingham A, Chand MA, Brown CS, et al. Severe respiratory illness caused by a novel coronavirus, in a patient transferred to the United Kingdom from the Middle East, September 2012. Euro Surveill 2012;17:20290.

4. Pollack MP, Pringle C, Madoff LC, et al. Latest outbreak news from ProMED-mail: novel coronavirus-Middle East. Int $J$ Infect Dis 2013;17:e143-4.

5. World Health Organization (WHO). Global Alert and Response (GAR). Ebola virus disease update-west Africa 2014 (cited 28 Aug 2014). http://www.who.int/csr/don/2014 0828 ebola/en/

6. Chughtai AA, Seale H, MacIntyre CR. Use of cloth masks in the practice of infection control-evidence and policy gaps. Int $J$ Infect Control 2013:9:1-12.

7. Quesnel LB. The efficiency of surgical masks of varying design and composition. Br J Surg 1975;62:936-40.

8. Maclntyre CR, Wang Q, Cauchemez S, et al. A cluster randomized clinical trial comparing fit-tested and non-fit-tested N95 respirators to medical masks to prevent respiratory virus infection in health care workers. Influenza Other Respir Viruses 2011;5:170-9.
9. Maclntyre $\mathrm{CR}$, Wang $\mathrm{Q}$, Seale $\mathrm{H}$, et al. A randomised clinical trial of three options for N95 respirators and medical masks in health workers. Am J Respir Crit Care Med 2013;187:960-6.

10. Chughtai $\mathrm{AA}$, Maclntyre $\mathrm{CR}$, Zheng $\mathrm{Y}$, et al. Examining the policies and guidelines around the use of masks and respirators by healthcare workers in China, Pakistan and Vietnam. $J$ Infect Prev 2015;16:68-74.

11. Chughtai AA, Seale $H$, Chi Dung $T$, et al. Current practices and barriers to the use of facemasks and respirators among hospital-based health care workers in Vietnam. Am J Infect Control 2015;43:72-7.

12. Pang $X, Z$ Zhu Z, Xu F, et al. Evaluation of control measures implemented in the severe acute respiratory syndrome outbreak in Beijing. JAMA 2003;290:3215-21.

13. Yang $\mathrm{P}$, Seale $\mathrm{H}$, Maclntyre $\mathrm{C}$, et al. Mask-wearing and respiratory infection in healthcare workers in Beijing, China. Braz $J$ Infect Dis 2011;15:102-8.

14. Horton R. Medical journals: evidence of bias against the diseases of poverty. Lancet 2003;361:712-13.

15. Maclntyre CR, Chughtai AA. Facemasks for the prevention of infection in healthcare and community settings. BMJ 2015;350:h694.

16. Chughtai AA, Seale H, MacIntyre CR. Availability, consistency and evidence-base of policies and quidelines on the use of mask and respirator to protect hospital health care workers: a global analysis. BMC Res Notes 2013;6:1-9.

17. Maclntyre C, Cauchemez S, Dwyer D, et al. Face mask use and control of respiratory virus transmission in households. Emerg Infect Dis 2009;15:233-41.

18. Buecher C, Mardy S, Wang W, et al. Use of a multiplex PCR/RTPCR approach to assess the viral causes of influenza-like illnesses in Cambodia during three consecutive dry seasons. J Med Virol 2010;82:1762-72 [Epub ahead of print 1 Sep 2010].

19. Higuchi R, Fockler C, Dollinger G, et al. Kinetic PCR analysis: realtime monitoring of DNA amplification reactions. Biotechnology $(N Y)$ 1993;11:1026-30 [Epub ahead of print 1 Sep 2010]

20. Hummel KB, Lowe L, Bellini WJ, et al. Development of quantitative gene-specific real-time RT-PCR assays for the detection of measles virus in clinical specimens. J Virol Methods 2006;132:166-73 [Epub ahead of print 11 Sep 2005].

21. Mackay IM. Real-time PCR in microbiology. Caister Academic Press, 2007.

22. Wang W, Cavailler $\mathrm{P}$, Ren $\mathrm{P}$, et al. Molecular monitoring of causative viruses in child acute respiratory infection in endemo-epidemic situations in Shanghai. J Clin Virol (PASCV) 2010;49:211-8.

23. Thi TN, Deback C, Malet I, et al. Rapid determination of antiviral drug susceptibility of herpes simplex virus types 1 and 2 by real-time PCR. Antiviral Res 2006;69:152-7.

24. Standards Australia Limited/Standards New Zealand. Respiratory protective devices. Australian/New Zealand Standard. AS/NZS 1716 2012.

25. Donner A, Klar N. Design and analysis of cluster randomization trials in health research. London: Oxford University Press Inc, 2000.

26. Campbell MK, Elbourne DR, Altman DG, et al. CONSORT statement: extension to cluster randomised trials. $B M J$ 2004;328:702-8.

27. Vittinghoff E, Glidden DV, Shiboski SC, et al. Regression methods in biostatistics. 2nd edn. New York: Springer-Verlag, 2012.

28. StataCorp. Stata 12 base reference manual. College Station, TX: Stata Press, 2011.

29. Osterholm MT, Moore KA, Kelley NS, et al. Transmission of Ebola viruses: what we know and what we do not know. mBio 2015;6: e00137-15.

30. Fisher EM, Noti JD, Lindsley WG, et al. Validation and application of models to predict facemask influenza contamination in healthcare settings. Risk Anal 2014;34:1423-34.

31. Li Y, Wong T, Chung J, et al. In vivo protective performance of N95 respirator and surgical facemask. Am J Ind Med 2006;49:1056-65.

32. Dick EC, Jennings LC, Mink KA, et al. Aerosol transmission of rhinovirus colds. J Infect Dis 1987;156:442-8.

33. Bischoff WE. Transmission route of rhinovirus type 39 in a monodispersed airborne aerosol. Infect Control Hosp Epidemiol 2010;31:857-9.

34. Institute of Medicine (IOM). Reusability of Facemasks During an Influenza Pandemic: Facing the Flu-Committee on the Development of Reusable Facemasks for Use During an Influenza Pandemic. National Academy of Sciences, 2006.

35. Center for Disease Control and Prevention and World Health Organization. Infection control for viral haemorrhagic fevers in the African health care setting. Atlanta: Centers for Disease Control and Prevention, 1998:1-198. 
36. World Health Organization (WHO). Guidelines for the prevention of tuberculosis in health care facilities in resource limited settings, 1999.

37. Weaver GH. Droplet infection and its prevention by the face mask. $J$ Infect Dis 1919;24:218-30.

38. Maclntyre CR, Chughtai AA, Seale $\mathrm{H}$, et al. Respiratory protection for healthcare workers treating Ebola virus disease (EVD): are facemasks sufficient to meet occupational health and safety obligations? Int J Nurs Stud 2014;51: $1421-6$
39. Center for Disease Control and Prevention (CDC). Guidance on Personal Protective Equipment To Be Used by Healthcare Workers During Management of Patients with Ebola Virus Disease in U.S Hospitals, Including Procedures for Putting On (Donning) and Removing (Doffing). 2014 (cited 23 Oct 2014). http://www.cdc.gov/ vhf/ebola/hcp/procedures-for-ppe.html

40. World Health Organiszation (WHO). Infection prevention and control guidance for care of patients in health-care settings, with focus on Ebola. 2014 (cited 23 Oct 2014). http://www.who.int/csr/resources/ publications/ebola/filovirus infection_control/en/ 